\title{
Minimally-invasive Tubular Surgery Versus Conventional Surgery in the Treatment of Spinal Metastasis: a Retrospective Case-control Study
}

\author{
Xuedong Shi \\ Peking University First Hospital \\ Yunpeng Cui ( $\square$ luful1987@163.com) \\ Peking University First Hospital \\ Chuan Mi \\ Peking University First Hospital \\ Bing Wang \\ Peking University First Hospital \\ Chunwei Li \\ Peking University First Hospital \\ Yuanxing Pan \\ Peking University First Hospital \\ Yunfei Lin \\ Peking University First Hospital
}

\section{Research Article}

Keywords: Spinal metastasis, minimally-invasive tubular surgery, minimally invasive spine surgery, conventional surgery, tubular retractor, hypo-vascular tumor

Posted Date: April 26th, 2021

DOI: https://doi.org/10.21203/rs.3.rs-434880/v1

License: (c) (i) This work is licensed under a Creative Commons Attribution 4.0 International License. Read Full License 


\section{Abstract}

Background: This study aims to evaluate the perioperative safety and efficacy of minimally-invasive tubular surgery for spinal metastasis with different blood supply.

Methods: 72 patients with spinal metastasis between January 2011 to June 2020 were retrospectively reviewed. 14 patients underwent minimally-invasive tubular surgery (Mini-invasive group), and 58 patients underwent conventional surgery (Conventional group). T-test and Mann-Whitney $U$ test was used to evaluate the difference in demographic and perioperative data between the two groups.

Results: Baseline characteristics did not differ significantly between the two groups except for the Tokuhashi score ( $p=0.036)$. Overall, conventional group had significantly more blood loss $(P=0.001)$, blood transfused $(P=0.027)$, drainage $(P<0.001)$, and longer time of drainage tube $(P<0.001)$, postoperative hospitalization $(P=0.002)$ compared with the mini-invasive group. Sub-analysis showed that for patients with hypo-vascular tumor, trans-channel decompression surgery had all advantages mentioned above. For patients with hyper-vascular tumor, trans-channel decompression surgery only had advantages on the drainage related events. Patients with hyper-vascular tumor had significantly more blood loss compared with patients with hypo-vascular tumor among mini-invasive group.

Conclusion: In selected cases with spinal metastasis, minimally-invasive tubular surgery is safe and effective for patients with spinal metastasis. Patients with hypo-vascular tumor were more suitable for this technique with less blood loss, less blood transfused, less drainage and shorter postoperative hospitalization.

\section{Background}

The incidence of spinal metastasis has remarkably increased due to increased population and extended patient survival [1]. Treatment of spinal metastasis depends on the global performance status, expected survival, and neurological and mechanical factors of the patients [2]. Conventional surgery is useful for managing patients with spinal metastasis, such as metastatic spinal cord compression and intractable pain due to spinal instability [3, 4]. However, the incidence of postoperative complications is higher [5]. Those patients need a relatively more extended period to recover, and the subsequent treatment, such as radiation, chemotherapy, or targeted drug, has to be postponed. Minimally invasive spine surgeries are technique characterized by less physiological insult and fewer postoperative complications, allowing early mobilization and rapid recovery [6]. These techniques, such as percutaneous pedicle screw fixation with or without mini-open technique, have been applied in managing symptomatic spinal metastases and achieved positive therapeutic results [7-13].

Foley KT first proposed mini-invasive transforaminal lumbar interbody fusion (Mis-TLIF) through an expandable tubular retractor. Minimallyinvasive tubular surgery constituted the core of this surgical technique and was widely used in treating degenerative spinal diseases. Mis-TLIF can achieve the same therapeutic effect in terms of safety, pain reduction, and neurological outcome compared to conventional surgery [14]. Whether this is the case for spinal metastases' surgical treatment has not yet been examined thoroughly. Few studies had reported that Minimally-invasive tubular surgery was safe and effective for patients with spinal metastases [15-19]. However, there was no clear statement on the selection of patients with primary tumor of different blood supply. For a hyper-vascular tumor, whether the Minimally-invasive tubular surgery still have advantages over conventional surgery? The present study aimed to evaluate the perioperative safety and efficacy of minimally-invasive tubular surgery for patients with primary tumor of different vascular supply and guide surgeons to select the best candidates.

\section{Methods}

\section{Study design and selection criteria}

This study was a retrospective study of patients with spinal metastasis requiring surgical intervention. From January 2011 to June 2020 , a total of 352 patients underwent decompression surgery were included as our initial cases. We excluded those patients with the anterior surgery (22), artificial vertebral reconstruction (27), multi-segment surgery (150), single segment surgery above T7 (58) and American Spinal Injury Association Impairment Scale (AIS) lower than D (23). Finally, 72 patients meet the criteria. These patients were assigned to 2 groups according to the surgical procedure: mini-invasive group $(n=14)$ comprised of patients who underwent minimally-invasive tubular surgery; conventional group $(n=58)$ comprised of patients who underwent conventional surgery. The flow of patient enrolment is shown in Fig. 1.

All patients underwent a physical examination, X-ray, and Magnetic Resonance Imaging (MRI) or computer tomography to confirm the lesion's location. Their blood samples were taken for routine test before surgery. Surgical indications were intractable pain due to spinal instability and myelopathy/ radiculopathy caused by spinal metastasis, those not responding to conservative treatment such as radiation and chemotherapy. The surgery option was determined by multidisciplinary cooperation, composing of neuro-radiologist, spinal tumor surgeon, and oncologist. 


\section{Data collection}

Patients' characteristics, including demographic information, Body Mass Index (BMI), American Society of Anesthesiologists (ASA) score, primary tumor type, location of the lesion, grade of epidural compression, Tokuhashi score, Spinal Instability Neoplastic Score (SINS) score, Karnofsky score, Eastern Cooperative Oncology Group (ECOG), Visual Analogue Scale (VAS), ambulatory status and neurological function according to AIS were carefully extracted from their electronic medical records. Metastasis from renal, liver and thyroid tumor were assigned to hyper-vascular tumor [20]. Perioperative data including operative time, blood loss, preoperative arterial embolism, patients with blood transfusion and milliliter transfused, surgically related complications, total milliliter of drainage, postoperative hospitalization, and laboratory data including hemoglobin (HGB), hematocrit (Hct) and albumin (Alb) were also extracted. Follow-up data including VAS, Karnofsky score, and ECOG postoperative 3 months were collected.

\section{Surgical techniques and illustrative cases}

All surgeries were performed by experienced spinal tumor surgeon under general anesthesia. The indication for transfusion was HGB less than $80 \mathrm{~g} / \mathrm{L}$ or less than $90 \mathrm{~g} / \mathrm{L}$ for coronary disease patients.

Minimally-invasive tubular surgery was performed for single-segment decompression at the lower thoracic or lumbar spine through a unilateral paraspinal muscle space approach (Figure. 2). Structure such as spinous processes, lamina, and facet joint on the other side, and muscle tissue were protected. Pedicle screws were percutaneously placed under fluoroscopy. The incision was made $2 \mathrm{~cm}$ or more lateral from the decompressed pedicle's skin projection, depending on the degree of obesity. Tubular retractor was placed lateral side of the pedicle with the help under the guidance of K-wire. Trans channel laminectomy or corpectomy was performed by piecemeal excision.

Conventional surgery was performed via the median posterior approach, and paravertebral muscles were stripped to expose the lamina and facet joints (Figure. 3). After Pedicle screws were inserted, laminectomy or corpectomy was performed by piecemeal excision.

\section{Statistical Analysis}

Continuous variables were presented as mean (standard \pm deviation) when they were in the normal distribution and median (range) when they were not. T-test or Mann-Whitney $U$ test was used to detect the difference among continuous variables. The differences among the categorical variables between different groups were analyzed using the chi-square test. All tests were 2-sides. Delete cases with missing values during the statistical process. A p-value $<0.05$ was considered statistically significant. All statistical analyses were performed with the IBM SPSS Statistics 25 (IBM Corporation, Armonk, NY.).

\section{Results}

The detailed characteristics were shown in Table 1. Except for Tokuhashi score, we found no significant differences in the demographic, preoperative tumor-related data, preoperative functional status, and laboratory data between two groups. Conventional group had significantly higher Tokuhashi score compared with mini-invasive group. 
Table 1

Baseline characteristics comparing between mini-invasive and conventional groups

Characteristic

Mini-invasive

Conventional

$P$

( $n=14)$

$(n=58)$

Gender

Female

5

22

0.878

Male

9

36

Age, mean $\pm S D$

$67 \pm 3$

$63 \pm 1$

0.157

BMI, median (range)

24 (14-28)

$23(17-32)$

0.598

ASA score

।

(1)

II

0

1

0.746

III

10

36

4

21

Tumor pathology

Renal 3

8

0.722

Lung

4

Prostate

hematological malignancy

$2 \quad 11$

Uroepithelium

Digestive tract malignancy

Hepatobiliary malignancy

Breast

Gynecological malignancy

$3 \quad 9$

Blood supply

Hypervascular (renal, Hepatobiliary)

3

12

0.951

Non-hyper vascular (lung, etc.)

11

46

Compression grade (Bilsky)

$1 b$

1

1

0.266

$1 \mathrm{c}$

2

3

9

7

3

1

34

16

Location of the lesion

Lumbar spine

623

0.826

Thoracic spine

8

Tokuhashi score, mean \pm SD

$7.6 \pm 0.6$

35

SINS score, mean \pm SD

$10.4 \pm 0.3$

$8.9 \pm 0.3$

0.036

$9.5 \pm 0.2$

0.092

Ambulatory status

Nonambulatory

3

21

0.292

SINS, Spinal Instability Neoplastic Score; ASA, American Society of Anesthesiologists; BMI, Body Mass Index; AIS, American Spinal Injury Association Impairment Scale; ECOG, Eastern Cooperative Oncology Group; HGB, haemoglobin; Hct, haematocrit; Alb, albumin; VAS, Visual Analogue Scale. 


\begin{tabular}{|c|c|c|c|}
\hline Characteristic & $\begin{array}{l}\text { Mini-invasive } \\
(n=14)\end{array}$ & $\begin{array}{l}\text { Conventional } \\
(n=58)\end{array}$ & $P$ \\
\hline Ambulatory & 11 & 37 & \\
\hline \multicolumn{4}{|l|}{ AIS } \\
\hline D & 2 & 11 & \multirow[t]{2}{*}{0.683} \\
\hline E & 12 & 47 & \\
\hline VAS, median (range) & $8(7-9)$ & $8(6-9)$ & 0.451 \\
\hline Karnofsky score, median (range) & $60(40-70)$ & $60.0(40-70)$ & 0.137 \\
\hline ECOG score, median (range) & $2(2-4)$ & $2(2-4)$ & 0.422 \\
\hline $\mathrm{HGB}(\mathrm{g} / \mathrm{L})$, mean $\pm \mathrm{SD}$ & $120 \pm 6$ & $130 \pm 3$ & 0.093 \\
\hline Hct (\%), mean \pm SD & $36.1 \pm 1.9$ & $37.9 \pm 0.7$ & 0.313 \\
\hline Alb (g/L), median (range) & $38.3(28.2-45.2)$ & $40.9(23.7-49.4)$ & 0.123 \\
\hline
\end{tabular}

The surgical outcomes were shown in Table 2. There were no significant differences in preoperative arterial embolism rate, operation time, blood transfusion rate, and complications rate between two groups. Conventional group had significantly more blood loss (1200 (300-3500) $\mathrm{ml}$ VS 550 (50-2500) $\mathrm{ml})$, blood transfused during operation (800 (0-2400) $\mathrm{ml}$ VS 400 (0-1200) $\mathrm{ml}$ ) and within 3 days post-operation (800 (0$3200) \mathrm{ml}$ VS $400(0-1200) \mathrm{ml})$, drainage at the first-day $(286 \pm 17 \mathrm{ml} \mathrm{VS} 57 \pm 10 \mathrm{ml})$ and total drainage $(824 \pm 41 \mathrm{ml}$ VS $141 \pm 32 \mathrm{ml})$ compared with M group. C Group had longer drainage time (7 (4-12) days VS $3(2-5)$ days) and postoperative hospitalization (11.5 (6-41) days VS 7.5 (4-16) days) compared with mini-invasive group. 
Table 2

Operative related data comparing between mini-invasive and conventional groups

\begin{tabular}{|c|c|c|c|}
\hline Characteristic & $\begin{array}{l}\text { Mini-invasive } \\
(n=14)\end{array}$ & $\begin{array}{l}\text { Conventional } \\
(n=58)\end{array}$ & $P$ \\
\hline \multicolumn{4}{|l|}{ Preoperative embolism } \\
\hline Yes & 2 & 6 & \multirow[t]{2}{*}{0.674} \\
\hline No & 12 & 52 & \\
\hline Operation time, median (range) & $230(172-337)$ & $239(161-499)$ & 0.760 \\
\hline \multicolumn{4}{|l|}{ Complication } \\
\hline Wound infection & 0 & 1 & 0.621 \\
\hline Dural tear & 2 & 5 & 0.521 \\
\hline Screw displacement & 1 & 0 & 0.437 \\
\hline Blood loss (ml), median (range) & $550(50-2500)$ & $1200(300-3500)$ & 0.001 \\
\hline \multicolumn{4}{|l|}{ Blood transfusion (patients) } \\
\hline Yes & 10 & 48 & \multirow[t]{2}{*}{0.336} \\
\hline No & 4 & 10 & \\
\hline \multicolumn{4}{|l|}{ Blood transfusion (ml) median (range) } \\
\hline Intraoperative & $400(0-1200)$ & $800(0-2400)$ & 0.035 \\
\hline Within 3 days post operation & $400(0-1200)$ & $800(0-3200)$ & 0.027 \\
\hline \multicolumn{4}{|l|}{ Drainage } \\
\hline First day $(\mathrm{ml})$, mean \pm SD & $57 \pm 10$ & $286 \pm 17$ & $<0.001$ \\
\hline Total amount $(\mathrm{ml})$, mean \pm SD & $141 \pm 32$ & $824 \pm 41$ & $<0.001$ \\
\hline Time (day), median (range) & $3(2-5)$ & $7(4-12)$ & $<0.001$ \\
\hline Postoperative hospitalization, median (range) & $7.5(4-16)$ & $11.5(6-41)$ & 0.002 \\
\hline
\end{tabular}

We conducted a sub-analysis to clarify the relevance of the tumor's vascular supply to this mini-invasive technique (Table 3 ). For patients with hypo-vascular tumor, trans- channel decompression had significantly advantages on blood loss (400 (50-700)ml VS 1100 (300-3500)ml), blood transfused during operation (400 (0-800) ml VS 800 (0-2400) ml) and within 3 days post-operation (400 (0-800) ml VS 800 (0-3200) ml), drainage at the first-day $(66 \pm 12 \mathrm{ml}$ VS $308 \pm 19 \mathrm{ml})$, total drainage (137 $\pm 40 \mathrm{ml}$ VS $812 \pm 48 \mathrm{ml})$, drainage time (3 (2-4) days VS 6 (4-11) days) and postoperative hospitalization (7 (4-16) days VS 11.5 (6-41) days) compared with conventional procedure. However, for patients with hyper-vascular tumor, trans- channel decompression only had significantly advantage on drainage at the first-day (32 \pm 9 ml VS $241 \pm 22$ $\mathrm{ml})$, total drainage (152 $\pm 61 \mathrm{ml}$ VS $883 \pm 126 \mathrm{ml})$, drainage time (4 (3-5) days VS 7 (6-9) days) compared with conventional procedure. Among the mini-invasive group, patients with hypo-vascular tumor had few operation time, blood loss and blood transfused compared with patients with hyper-vascular tumor. Blood loss was statistically significant (400(50-700) ml VS 2200 (1000-2500) ml). 
Table 3

Sub-analysis of operative related data

\begin{tabular}{|c|c|c|c|c|c|c|c|c|c|}
\hline & Items & $\begin{array}{l}\text { Operation } \\
\text { time, } \\
\text { median } \\
\text { (range) }\end{array}$ & $\begin{array}{l}\text { Blood } \\
\text { loss } \\
\text { (ml), } \\
\text { median } \\
\text { (range) }\end{array}$ & $\begin{array}{l}\text { Intraoperative } \\
\text { Blood } \\
\text { transfusion } \\
\text { (ml) median } \\
\text { (range) }\end{array}$ & $\begin{array}{l}\text { Blood } \\
\text { transfusion } \\
\text { Within } 3 \\
\text { days post } \\
\text { operation } \\
\text { (ml) } \\
\text { median } \\
\text { (range) }\end{array}$ & $\begin{array}{l}\text { First day } \\
\text { Drainage } \\
(\mathrm{ml}), \\
\text { mean } \pm \\
\text { SD }\end{array}$ & $\begin{array}{l}\text { Total } \\
\text { Drainage } \\
(\mathrm{ml}) \text {, } \\
\text { mean } \pm \\
\text { SD }\end{array}$ & $\begin{array}{l}\text { Drainage } \\
\text { Time } \\
\text { (day), } \\
\text { median } \\
\text { (range) }\end{array}$ & $\begin{array}{l}\text { Postoperative } \\
\text { hospitalization, } \\
\text { median (range) }\end{array}$ \\
\hline \multirow[t]{2}{*}{$\begin{array}{l}\text { Renal } \\
\text { cell } \\
\text { cancer }\end{array}$} & Mini-invasive & $\begin{array}{l}290 \\
(221- \\
337)\end{array}$ & $\begin{array}{l}2200 \\
(1000- \\
2500)\end{array}$ & $800(0-1200)$ & $\begin{array}{l}800(0- \\
1200)\end{array}$ & $32 \pm 9$ & $152 \pm 61$ & $4(3-5)$ & $8(7-12)$ \\
\hline & Conventional & $\begin{array}{l}242 \\
(179- \\
375)\end{array}$ & $\begin{array}{l}1850 \\
(500- \\
3500)\end{array}$ & $\begin{array}{l}800(400- \\
1200)\end{array}$ & $\begin{array}{l}1000 \\
(400- \\
2000)\end{array}$ & $241 \pm 22$ & $\begin{array}{l}883 \pm \\
126\end{array}$ & $7(6-9)$ & $10(7-17)$ \\
\hline$P$ & & 0.630 & 1 & 0.776 & 0.376 & $<0.001$ & 0.008 & 0.012 & 0.376 \\
\hline \multirow[t]{2}{*}{$\begin{array}{l}\text { Hypo- } \\
\text { vascular } \\
\text { tumor }\end{array}$} & Mini-invasive & $\begin{array}{l}222 \\
(172- \\
320)\end{array}$ & $\begin{array}{l}400 \\
(50- \\
700)\end{array}$ & $400(0-800)$ & $\begin{array}{l}400(0- \\
800)\end{array}$ & $66 \pm 12$ & $137 \pm 40$ & $3(2-4)$ & $7(4-16)$ \\
\hline & Conventional & $\begin{array}{l}239 \\
(161- \\
499)\end{array}$ & $\begin{array}{l}1100 \\
(300- \\
3500)\end{array}$ & $800(0-2400)$ & $\begin{array}{l}800(0- \\
3200)\end{array}$ & $308 \pm 19$ & $812 \pm 48$ & $6(4-11)$ & $11.5(6-41)$ \\
\hline$P$ & & 0.436 & $<0.001$ & 0.031 & 0.030 & $<0.001$ & $<0.001$ & $<0.001$ & 0.007 \\
\hline \multirow[t]{2}{*}{$\begin{array}{l}\text { Mini- } \\
\text { invasive }\end{array}$} & $\begin{array}{l}\text { Hyper- } \\
\text { vaxcular }\end{array}$ & $\begin{array}{l}290 \\
(221- \\
337)\end{array}$ & $\begin{array}{l}2200 \\
(1000- \\
2500)\end{array}$ & $800(0-1200)$ & $\begin{array}{l}800(0- \\
1200)\end{array}$ & $32 \pm 9$ & $152 \pm 61$ & $4(3-5)$ & $8(7-12)$ \\
\hline & $\begin{array}{l}\text { Hypo- } \\
\text { vaxcular }\end{array}$ & $\begin{array}{l}222 \\
(172- \\
320)\end{array}$ & $\begin{array}{l}400(50- \\
700)\end{array}$ & $400(0-800)$ & $\begin{array}{l}400(0- \\
800)\end{array}$ & $66 \pm 12$ & $137 \pm 40$ & $3(2-4)$ & $7(4-16)$ \\
\hline$P$ & & 0.170 & 0.005 & 0.368 & 0.368 & 0.153 & 0.857 & 0.088 & 0.769 \\
\hline
\end{tabular}

Postoperative day 1 and day 3 parameters, including HGB, Hct, and Alb, were showed in Table 4 and Fig. 4. All parameters were significantly declined compared with preoperative and maintain a relatively stable level within 3 days post-operation. There were no significantly differences of HGB, Hct and Alb between two groups at postoperative day 1 and day 3. However, HGB, Hct and Alb declined more in the conventional group than the mini-invasive group, HGB declined more significantly. 
Table 4

Postoperative laboratory data and function comparing between mini-invasive and conventional groups

Characteristic

Mini-invasive

Conventional

$P$

$(n=14)$

$(n=58)$

Postoperative day 1 , mean \pm SD

HGB (g/L),

$102 \pm 4$

$98 \pm 2$

0.422

HGB decline ( $g / L)$

$18 \pm 5$

$31 \pm 3$

0.036

Hct (\%)

$30.3 \pm 1.3$

$28.7 \pm 0.6$

0.265

Hct decline (\%)

$5.9 \pm 1.4$

$9.2 \pm 0.8$

0.067

Alb (g/L)

$31.3 \pm 0.7$

$30.8 \pm 0.4$

0.617

Alb decline $(\mathrm{g} / \mathrm{L})$

$6.7 \pm 1.2$

$9.1 \pm 0.6$

0.088

Postoperative day 3 , mean \pm SD

HGB (g/L)

$97 \pm 5$

$96 \pm 2$

0.856

HGB decline ( $g / L)$

$19 \pm 9$

$33 \pm 4$

0.108

Hct (\%)

$29.3 \pm 1.9$

$28.2 \pm 0.6$

0.493

Hct decline (\%)

$5.3 \pm 2.7$

$10.4 \pm 1.1$

0.052

Alb (g/L)

$29.9 \pm 1.1$

Alb decline ( $\mathrm{g} / \mathrm{L})$

$6.9 \pm 1.9$

Discharge

Ambulatory status
Nonambulatory

0

14

Ambulatory

Change in ambulatory status

Improve

Same

Aggravate

AIS

D

E

Change in AIS

Improve

Same

Aggravate

VAS, median (range)

Postoperative 3 months

VAS, median (range)

Karnofsky score, median (range)

ECOG score, median (range)

3

11

0

\section{1}

13

1

\section{0}

$31.3 \pm 0.6$

0.274

$8.7 \pm 1.0$

0.397

54

17

0.555

41

0

5

0.857

53

7

0.599

13

51

$3(2-3)$

$3(2-4)$

0.206

$2(2-3)$
$80(60-80)$
$2(1-2)$

$3(2-4)$

0.096

70 (60-80)

0.387

$2(1-2)$

0.151

AIS, American Spinal Injury Association Impairment Scale; ECOG, Eastern Cooperative Oncology Group; VAS, Visual Analogue Scale; HGB, haemoglobin; Hct, haematocrit; Alb, albumin. 
There were no significant differences in functional improvement of ambulatory status and AIS between two groups. Postoperative VAS was significantly improved than preoperative in both groups and maintained at a stable level at 3 months post-operation. Karnofsky and ECOG score at 3 months post-operation was significant improvement compared with preoperative in both groups. There were no significant differences in VAS, Karnofsky score, and ECOG at 3 months post operation between two groups (Table 4, Fig. 4, Fig. 5).

\section{Discussion}

Minimally-invasive tubular surgery is an emerging technique applied in the treatment of patients with spinal metastasis. Previous studies reported that spine metastatic tumor could be safely resected through a tubular retractor with even less tissue destruction and quicker functional recovery than mini-open and conventional surgery. The present study provides a more comprehensive analysis to evaluate the perioperative safety and efficacy of this technique for patients with primary tumor of different vascular supply and guide surgeons to select the best candidates.

In this study, VAS, Karnofsky score, and ECOG of both groups were significantly improved after surgery. The difference between two groups was not statistically significant in VAS, Karnofsky score, ECOG, AIS and ambulatory status. Besides, HGB, Hct, and Alb were significantly declined post-operation in both groups. We attempted to compare the change of HGB, Hct, and Alb in both groups that may reflect the degree of surgical trauma. The results showed that HGB decreased more significant in conventional group after surgery. Similar to previously study [15-19], tubular surgery had significantly less blood loss, less blood transfused, less drainage and shorter postoperative hospitalization compared with the conventional surgery. However, we found intraoperative cauterize was difficult for patients with hyper-vascular tumor, such as renal cell cancer. Hyper-vascular tumor usually bleeded until they are completely resected. This finding encouraged us to conduct a subanalysis of our current data and the result showed that compared with hyper-vascular tumor such as renal cell, patients with hypo-vascular tumor would benefit more tubular surgery. This result was different from mini-open surgery and was mainly due to the limited vision under the tubular [7, 9]. Compared with mini-open surgery, tubular surgery had more stricter criteria on tumor type. For patients with hyper-vascular tumor, mini-open technique should be given priority. However, considering the advantages of more fast recovery of tubular surgery, preoperative arterial embolism or other intervention maybe performed to control the bleeding during operation for patients with hyper-vascular tumor. Although preoperative arterial embolism had been proven to reduce blood loss in conventional surgery, its role in tubular surgery remains to be confirmed by further studies.

The incidence of surgical complications for conventional surgery is higher in patients with symptomatic spinal metastases. Surgical trauma and perioperative complications often affect the continuity of subsequent treatment [5]. All minimally invasive spine surgeries are characterized by less physiological insult and early mobilization and rapid recovery. Our results suggested that patients who underwent tubular surgery recover faster than patients underwent conventional surgery. They would have more opportunity to receive adjuvant therapy such as radiotherapy at early stage postoperative, which played an essential role in the local tumor control [21]. Regrettably, our study showed tubular surgery had no significant advantage on operation time compared with the conventional surgery. Besides, the operation time and complication rate were relatively higher than the previous study performed by [19] and Nzokou A et al [17]. The complications of the tubular surgery were mainly dural tear. The learning curve for the utilization of an emerging technique must be taken into account when performing such a surgical strategy. Previous study focused on the learning curve of Mis TLIF and suggested that decompression through a tubular retractor was a higher technical requirement with relatively long operation time and more complications at the early stage. Silva PS et al. analyzed 150 patients with the degenerative lumbar disease who underwent MI-TLIF. The most frequent complication was a dural tear (5.32\%), and the complication rates were $33 \%$ and $20.51 \%$ for $50 \%$ and $90 \%$ learning milestones, respectively. They reported that $90 \%$ of the learning curve would be achieved around the 40th case [22]. The Operation time and complication rate will improve with the growth of this technique's learning curve in the future.

Short-segment fixation, not including the decompressed segment, was used at the initial stage in trans-channel decompression surgery. Besides, the transverse connection could not be applied due to limited exposure. Because of the poor holding power of the screws for patients with spinal metastasis and osteoporosis, displacement of the pedicle appeared during follow up. In order to avoid the occurrence of internal fixation failure, Harel et al. [15] and Zirai et al. [16] recommended extending the internal fixation segment or applying the cement screw technique. Besides, Harel et al. [15] suggested screw should be placed on the healthy side of the decompressed segment to convert the bridge structure into a classic three-point fixation, thereby increasing the holding power of the screws and overall stability.

There are limitations to the present study. First, it was limited by its retrospective and non-randomized nature and there would be a particular bias in patient selection. To minimize the selective bias, we strictly limited the screening criteria for patient's selection. Table 1 showed that there were no significant differences in the baseline characteristic between two groups. Second, the relatively small sample size may affect the outcomes available for analysis. A large-scale, prospective, randomized study should be carried out to validate these results. However, this study provides important information regarding applying this technique to treat spinal metastasis. In addition, this technique's characters make itself more suitable for patients with multiple comorbidities who are at high risk of perioperative complications [5].

Page 9/16 
In conclusion, this study showed that minimally-invasive tubular surgery is safe and effective for selected cases with spinal metastasis. Patients with hypo-vascular tumor were more suitable for this technique with less blood loss, less blood transfused, less drainage and shorter postoperative hospitalization.

\section{Conclusions}

In selected cases with spinal metastasis, minimally-invasive tubular surgery is safe and effective for patients with spinal metastasis. Patients with hypo-vascular tumor were more suitable for this technique with less blood loss, less blood transfused, less drainage and shorter postoperative hospitalization.

\section{Abbreviations}

SINS, Spinal Instability Neoplastic Score; VAS, Visual Analogue Scale; MISS, Minimally Invasive Spine Surgery; CS, Conventional Surgery; MRI, Magnetic Resonance Imaging; AIS, American Spinal Injury Association Impairment Scale, ASA, American Society of Anesthesiologists, ECOG, Eastern Cooperative Oncology Group; BMI, Body Mass Index; pre-OP, preoperative; post-OP, postoperative; HGB, haemoglobin; haematocrit, Hct; albumin, Alb;

\section{Declarations}

Ethical approval This retrospective study involving human participants was in accordance with the ethical standards of the institutional and national research committee and with the 1964 Helsinki Declaration and its later amendments or comparable ethical standards. The local Ethics Committee of Peking University First Hospital approved this study (2017[1417]).

Consent to participate All participants in this study were above 16 years of age. The need for written informed consent was waived by the Peking University First Hospital ethics committee due to retrospective nature of the study.

Consent for publication Not applicable.

Availability of data and material The datasets generated and/or analysed during the current study are not publicly available due privacy or ethical restrictions but are available from the corresponding author on reasonable request.

Competing interests The authors declare that they have no competing interests.

Funding No funding was received.

Authors' contributions Xd S conceived and designed the project. $\mathrm{Yp} \mathrm{C}$ and $\mathrm{YX} \mathrm{P}$ collected and organized the data, analyzed and interpreted the data. $Y p C$ and $X d S$ wrote the core of the manuscript. $C W L$ and $Y f L$ coordinated the statistical analyses. $C M$ and $B W$ revised the manuscript. $X \mathrm{~d} S$ revised and approved the final version of the manuscript. All authors read and approved the final manuscript.

Acknowledgements Not applicable

\section{References}

1. Siegel RL, Miller KD, Jemal A. Cancer statistics, 2019. CA Cancer J Clin. 2019;69(1):7-34.

2. Spratt DE, Beeler WH, de Moraes FY, Rhines LD, Gemmete JJ, Chaudhary N, et al. An integrated multidisciplinary algorithm for the management of spinal metastases: an International Spine Oncology Consortium report. Lancet Oncol. 2017;18(12):e720-30.

3. Patchell RA, Tibbs PA, Regine WF, Payne R, Saris S, Kryscio RJ, et al. Direct decompressive surgical resection in the treatment of spinal cord compression caused by metastatic cancer: A randomised trial. Lancet. 2005;366(9486):643-8.

4. Jansson KÅ, Bauer HCF. Survival, complications and outcome in 282 patients operated for neurological deficit due to thoracic or lumbar spinal metastases. Eur Spine J. 2006;15(2):196-202.

5. Finkelstein JA, Zaveri G, Wai E, Vidmar M, Kreder H, Chow E. A population-based study of surgery for spinal metastases. Survival rates and complications. J Bone Joint Surg Br. 2003;85(7):1045-50.

6. Tian NF, Wu YS, Zhang XL, Xu HZ, Chi YL, Mao FM. Minimally invasive versus open transforaminal lumbar the current evidence. Eur Spine J. 2013;22:174I-1749.

7. Miscusi M, Polli FM, Forcato S, Ricciardi L, Frati A, Cimatti M, et al. Comparison of minimally invasive surgery with standard open surgery for vertebral thoracic metastases causing acute myelopathy in patients with short- or mid-term life expectancy: Surgical technique and early clinical results. J Neurosurg Spine. 2015;22(5):518-25.

Page $10 / 16$ 
8. Fang T, Dong J, Zhou X, McGuire RA, Li X. Comparison of mini-open anterior corpectomy and posterior total en bloc spondylectomy for solitary metastases of the thoracolumbar spine Clinical article. J Neurosurg Spine. 2012;17(4):271-9.

9. Hansen-Algenstaedt N, Kwan MK, Algenstaedt P, Chiu CK, Viezens L, Chan TS, et al. Comparison Between Minimally Invasive Surgery and Conventional Open Surgery for Patients With Spinal Metastasis: A Prospective Propensity Score-Matched Study. Spine (Phila Pa 1976). 2017;42(10):789-97.

10. Hikata T, Isogai N, Shiono Y, Funao H, Okada E, Fujita N, et al. A Retrospective Cohort Study Comparing the Safety and Efficacy of Minimally Invasive Versus Open Surgical Techniques in the Treatment of Spinal Metastases. Clin Spine Surg. 2017;30(8):E1082-7.

11. Huang TJ, Hsu RWW, Li YY, Cheng CC. Minimal access spinal surgery (MASS) in treating thoracic spine metastasis. Spine (Phila Pa 1976). 2006;31(16):1860-3.

12. Kumar N, Malhotra R, Maharajan K, Zaw AS, Wu H, Makandura MC, et al. Metastatic Spine Tumor Surgery A Comparative Study of Minimally Invasive Approach Using Percutaneous Pedicle Screws Fixation Versus Open Approach. Clin Spine Surg. 2017;30:E1015-21.

13. D. L, D. C. Posterior thoracic corpectomy with cage reconstruction for metastatic spinal tumors: Comparing the mini-open approach to the open approach. J Neurosurg Spine. 2015;23(2):217-27.

14. Holly, Langston T.1. Holly LT, Schwender JD, Rouben DP, Foley KT. Minimally invasive transforaminal lumbar interbody fusion: indications, technique and complications. NF 2006;20(3).

15. R. H, O. D, N. K. Minimally invasive spine metastatic tumor resection and stabilization: New technology yield improved outcome. Biomed Res Int. 2015;2015.

16. Zairi F, Arikat A, Allaoui M, Marinho P, Assaker R. Minimally invasive decompression and stabilization for the management of thoracolumbar spine metastasis: Clinical article. J Neurosurg Spine. 2012;17(1):19-23.

17. Nzokou A, Weil AG, Shedid D. Minimally invasive removal of thoracic and lumbar spinal tumors using a nonexpandable tubular retractor: Clinical article. J Neurosurg Spine. 2013;19(6):708-15.

18. Deutsch H, Boco T, Lobel J. Minimally invasive transpedicular vertebrectomy for metastatic disease to the thoracic spine. J Spinal Disord Tech. 2008;21(2):101-5.

19. Schwab JH, Gasbarrini A, Cappuccio M, Boriani L, De lure F, Colangeli S, et al. Minimally Invasive Posterior Stabilization Improved Ambulation and Pain Scores in Patients with Plasmacytomas and/or Metastases of the Spine. Int J Surg Oncol. 2011;2011:1-5.

20. Kato S, Hozumi T, Takaki Y, Yamakawa K, Goto T, Kondo T. Optimal schedule of preoperative embolization for spinal metastasis surgery. Spine (Phila Pa 1976). 2013;38(22):1964-9.

21. Sandhu N, Benson KRK, Kumar KA, Eyben R V., Chang DT, Gibbs IC, et al. Local control and toxicity outcomes of stereotactic radiosurgery for spinal metastases of gastrointestinal origin. J Neurosurg Spine. 2020;33(1):87-94.

22. Silva PS, Pereira P, Monteiro P, Silva PA, Vaz R. Learning curve and complications of minimally invasive transforaminal lumbar interbody fusion. Neurosurg Focus. 2013;35(2).

\section{Figures}


Patients underwent surgery for metastatic spine disease from

January 2011 to June $2020 \quad(n=352)$

Exclude:

Anterior surgery $(\mathrm{n}=22)$

Partial or total corpectomy with artificial vertebral reconstruction $(\mathrm{n}=27)$

Multi-segment surgery $(\mathrm{n}=150)$

Single segment surgery above T7 (58)

Single segment surgery with AIS lower than

D (23)

Patients with single-segment decompression at the lower thoracic and lumbar spine and American Spinal Injury Association

Impairment Scale (AIS) $>=\mathrm{D}(\mathrm{n}=72)$

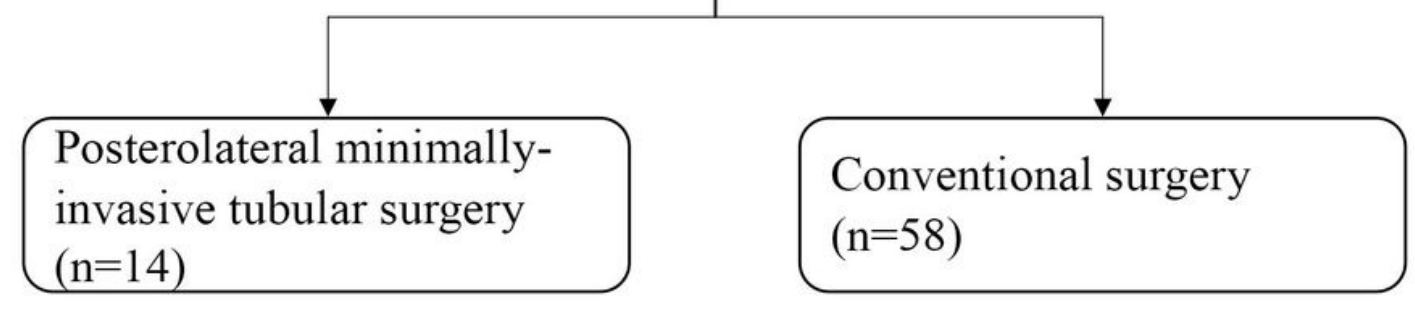

Figure 1

The flowchart of patient inclusion. 

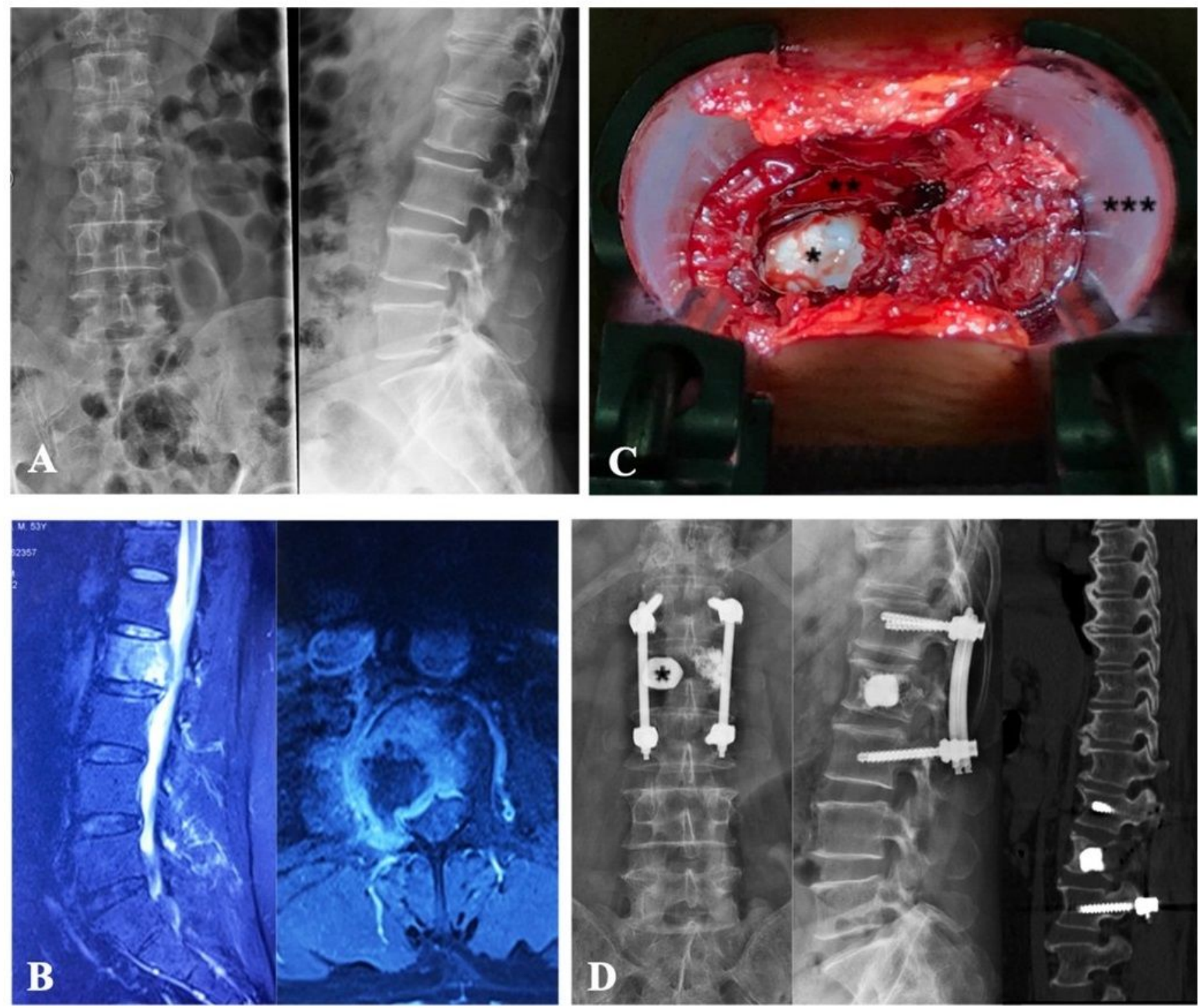

Figure 2

Illustration of minimally-invasive tubular surgery. A, Preoperative X-ray showing bone destruction of L2 vertebra. B, Preoperative MRI showing metastatic epidural spinal cord compression due to collapsed L2 metastatic lesion. C, minimally invasive decompression was performed through an expandable tubular retractor. D, Postoperative X-ray, and CT scan were showing the decompression site and implants. (asterisk, bone cement; double asterisk, dural sac; triple asterisk, cephalic) 

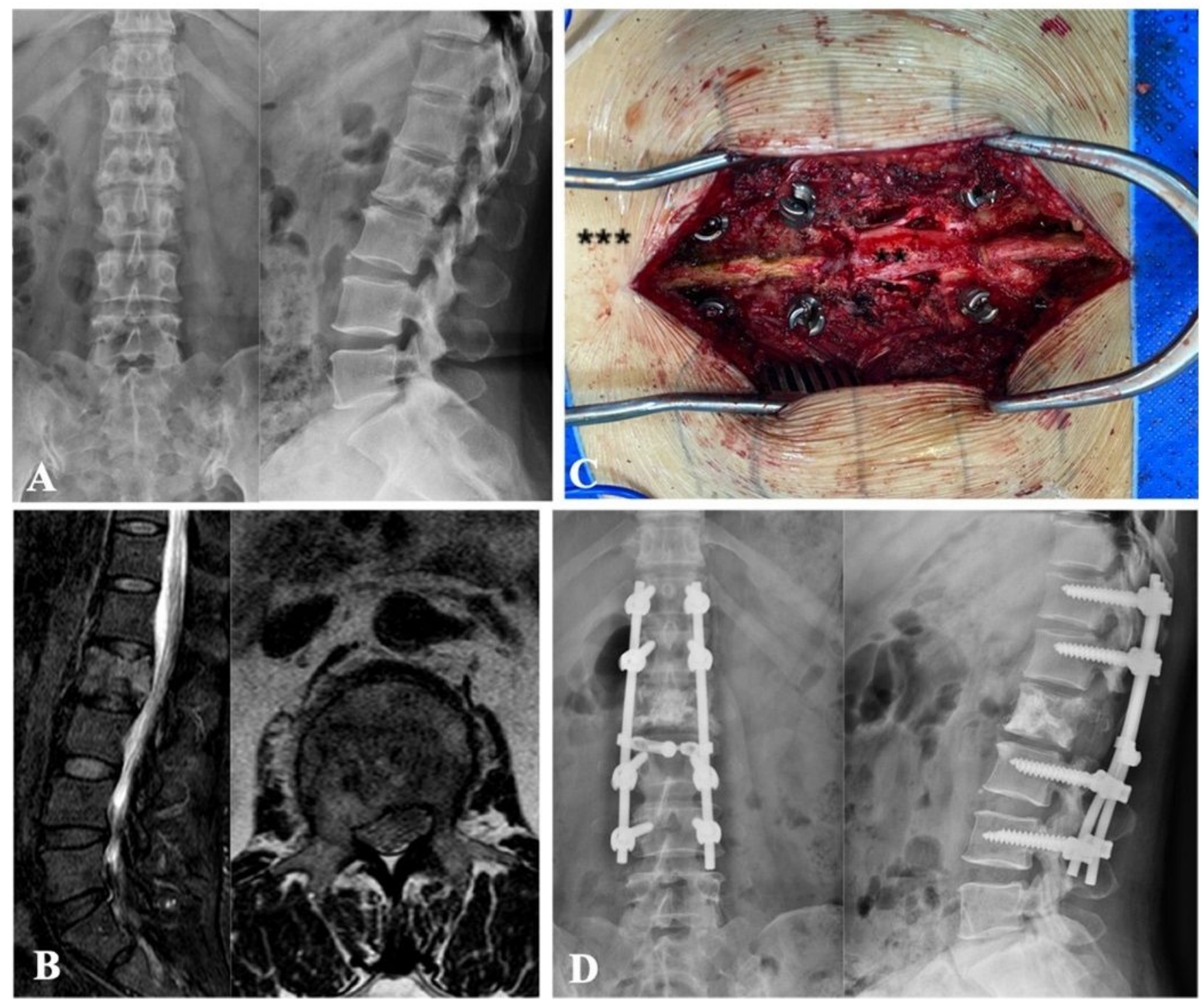

\section{Figure 3}

Illustration of conventional surgery. A, Preoperative X-ray showing bone destruction of L2 vertebra. B, Preoperative MRI showing metastatic epidural spinal cord compression due to collapsed L2 metastatic lesion. C, conventional open decompression was performed through a posterior central incision. D, Postoperative X-ray showing the implants. (double asterisk, dural sac; triple asterisk, cephalic) 
VAS

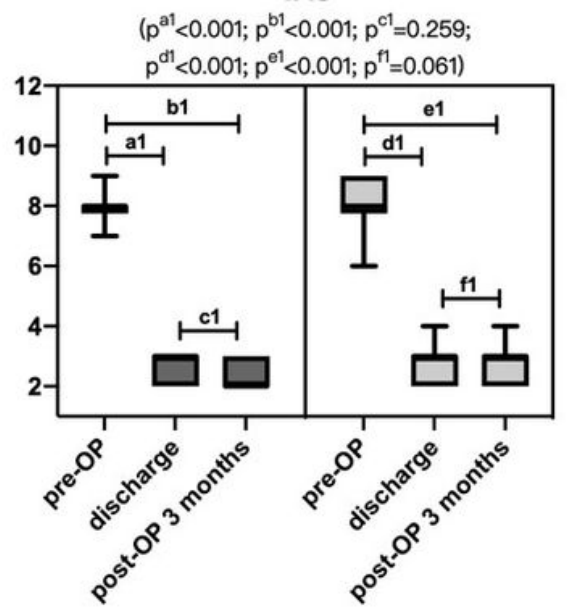

HGB (g/L)

$\left(p^{\mathrm{a} 1}=0.024 ; \mathrm{p}^{\mathrm{b} 1}=0.025 ; \mathrm{p}^{\mathrm{c} 1}=0.443\right.$;

$\mathrm{p}^{\mathrm{di}}<0.001 ; \mathrm{p}^{\text {e1 }}<0.001 ; \mathrm{p}^{\mathrm{f1}}=0.539$ )

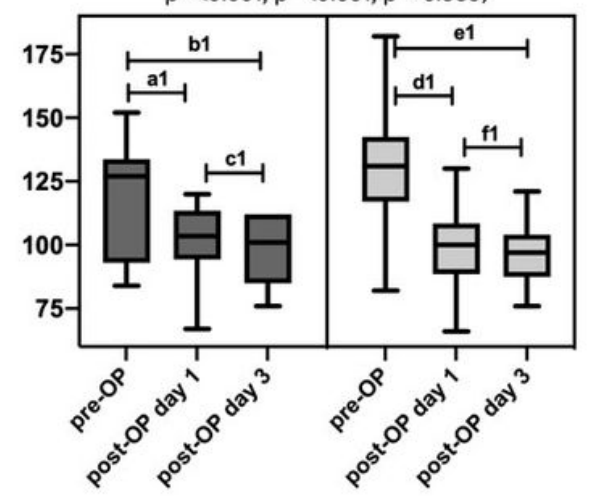

Karnofsky score

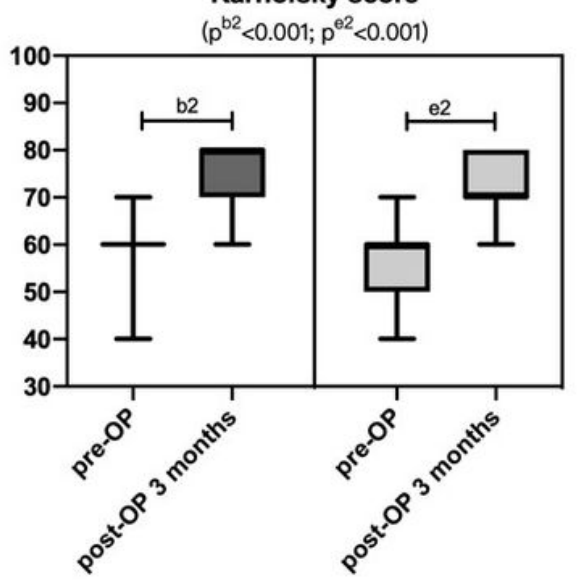

Hct (\%)

$\left(p^{a 2}=0.024 ; p^{b 2}=0.016 ; p^{c 2}=0.666 ;\right.$

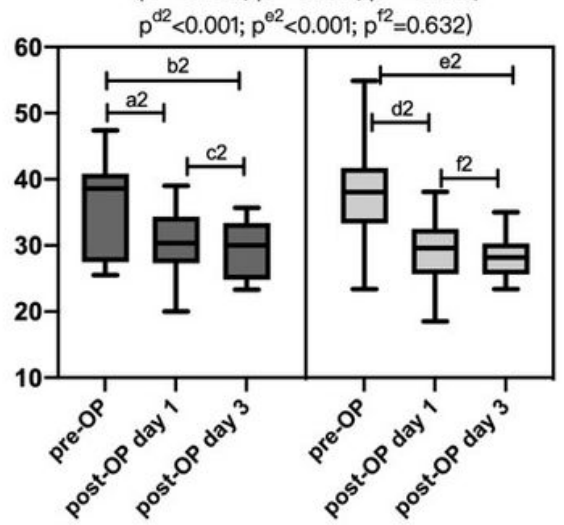

ECOG score

$\left(p^{b 3}=0.043 ; p^{e 3}<0.001\right)$

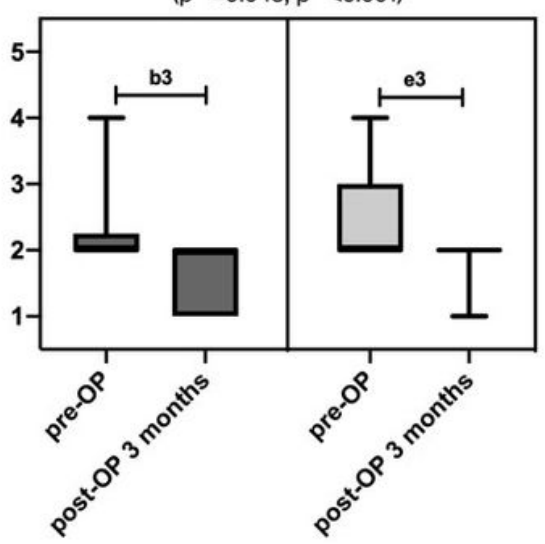

Alb (g/L)

$\left(p^{a 3}<0.001 ; p^{b 3}=0.001 ; p^{c 3}=0.299\right.$;

$\left.p^{d 3}<0.001 ; p^{e 3}<0.001 ; p^{f 3}=0.517\right)$

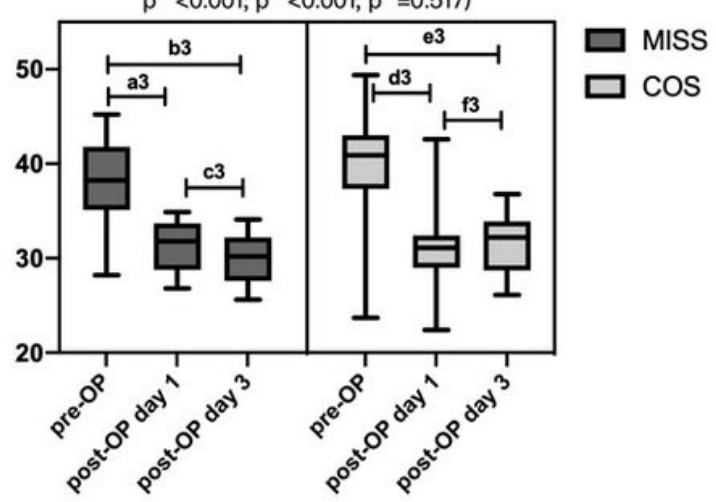

Figure 4

The perioperative HGB, Hct, Alb, VAS, Karnofsky, and ECOG scores of patients in mini-invasive and conventional groups. (Box and whiskers: min to max). 
Ambulatory status $(p<0.001)$
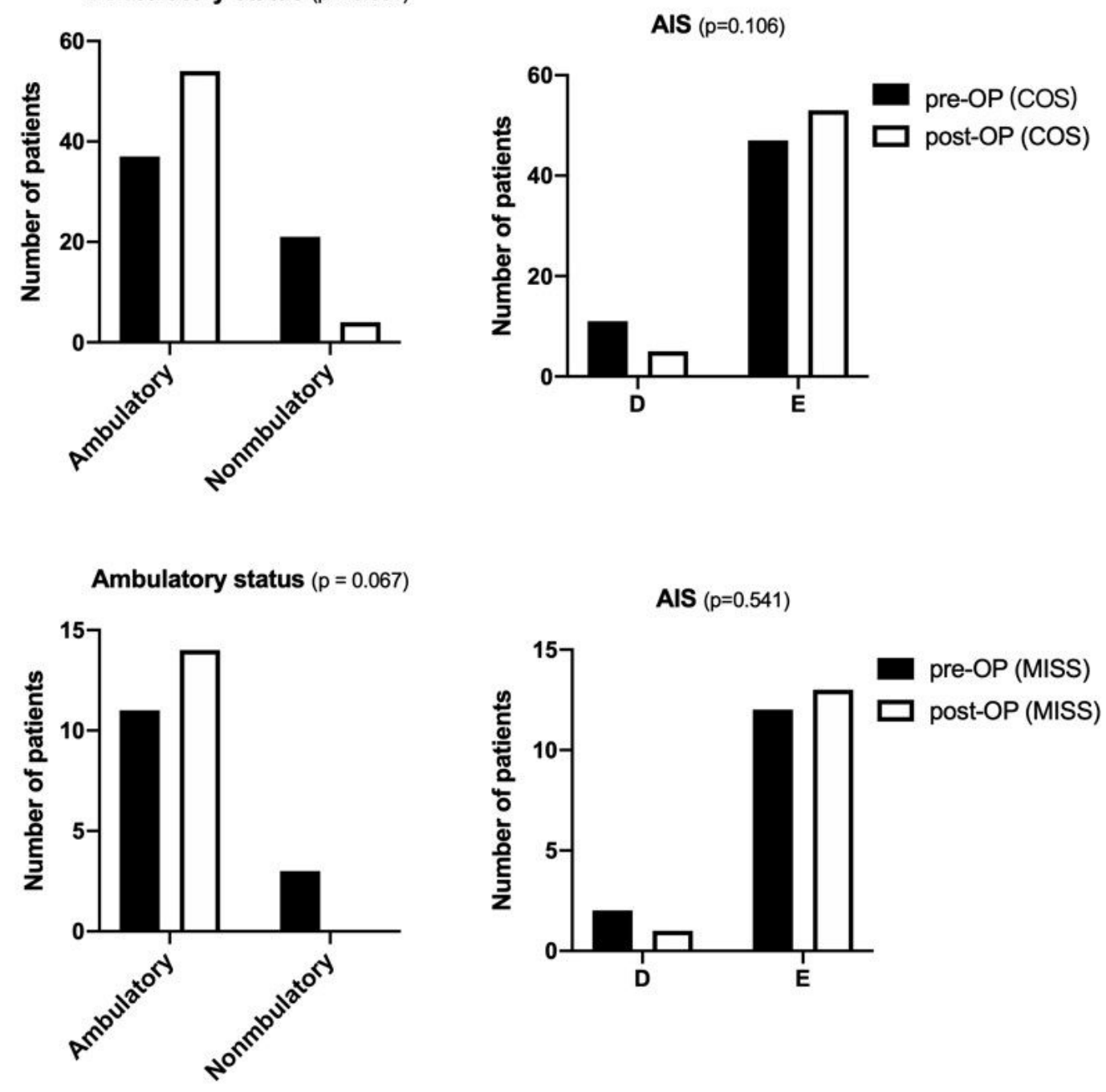

Figure 5

The pre and post-operative Ambulatory status and AIS of MISS and COS group of patients in mini-invasive and conventional groups. (Box and whiskers: min to max). 